\title{
A OFERTA DE CICLOS DE LEITURA EM LÍNGUA INGLESA NA FORMAÇÃO CONTINUADA
}

\author{
THE OFFERING OF READING CYCLES IN ENGLISH IN A \\ CONTINUING EDUCATION PROJECT
}

\section{LA OFERTA DE CICLOS DE LECTURA EN INGLÉS EN LA FORMACIÓN CONTINUADA}

\author{
Lady Lourdes Soares Medeiros ${ }^{1}$ \\ Jackson Santos Vitória de Almeida ${ }^{2}$ \\ Maralice Souza Neves ${ }^{3}$
}

\begin{abstract}
Resumo: Esta pesquisa parte de ações que promovem a leitura literária por meio da oferta de ciclos de mediação em língua inglesa em um projeto de extensão universitária. A conclusão é que a posição de mediador afeta o ensino-aprendizagem do docente.
\end{abstract}

Palavras-chave: Leitura literária; língua inglesa; formação continuada.

\begin{abstract}
This research starts from actions that put forward literary reading in continuing education by cycles of mediation in English in a university extra-mural project. The conclusion is that the position of mediator causes effects in the teacher's teaching-learning process.
\end{abstract}

Keywords: Literary reading; english language; continuing education.

Resumen: Esa investigación parte de acciones de promoción de lectura en la formación continuada por medio de los ciclos de mediación en inglés en un proyecto de extensión universitaria. La conclusión es que la posición que asume el mediador provoca efectos importantes en el proceso de enseñanza-aprendizaje del docente.

Palabras clave: Lectura literaria; inglés; formación continuada.

\section{Introdução}

Essa pesquisa reúne em seu escopo a motivação de se concretizar ações de promoção de leitura em língua inglesa nos espaços de Formação Continuada (FC) por meio de Ciclos de Mediação de Leitura em Língua Inglesa (CMLLI) para maior implicação dos docentes a literatura e com o desenvolvimento da mediação de leitura em língua inglesa (LI). O levantamento de dados fomenta as análises dos ciclos no ConCol na pesquisa de doutoramento "Leitura em Ação com Professores de Língua Inglesa na Formação Continuada”, desenvolvida pelo doutorando Jackson Almeida (professor-pesquisador-mediador) sob a orientação da professora doutora Maralice Neves (professora-coordenadora-mediadora) do Programa Interfaces da Formação em Línguas Estrangeiras e orientadora no programa de pós-graduação em Estudos Linguísticos na Faculdade de Letras (FALE) da Universidade Federal de Minas Gerais (UFMG). A pesquisa é resultado da ação de iniciação científica voluntária de uma English Assistant participante de 2018 a 2019, no Projeto ContinuAÇÃO Colaborativa (CONCOL), que pertence ao Programa Interfaces. Foi fundado em 2011 na FALE-UFMG para promover FC com professores de LI da rede de educação básica pública e privada da grande Belo Horizonte.

\footnotetext{
${ }^{1}$ Universidade Federal de Minas Gerais (UFMG).

${ }^{2}$ Universidade Federal de Minas Gerais (UFMG).

${ }^{3}$ Universidade Federal de Minas Gerais (UFMG).
} 
Busca-se por meio deste artigo apresentar como os CMLLI produzem efeitos na posição professor-mediador na FC. A trajetória teórico-metodológica está ancorada nos estudos da Pedagogia do Teatro (KOUDELA, 1999; PEROBELLI, 2013; SPOLIN, 2006), estudos da Performance (SCHECHNER, 2006), Psicanálise Freudo-lacaniana (FREUD, 1996; LACAN, 1998), Formação de Professores (ALMEIDA, 2016; NEVES, 2021), Leitura (COSSON, 2019; FREIRE, 1995; FREITAS, 2012) e Literatura (CANDIDO, 2004).

As análises dos ciclos foram feitas por meio da materialidade discursiva transcrita (CASTILHO, 1998) a partir de depoimentos de sete professores gravados em áudio e vídeo durante três Ciclos de Leitura realizados em 2018 e 2019. As imagens e registros de leitura dos acontecimentos (RLA) coletados no processo e compilados em forma de Diário de Pesquisa (DP) estão disponíveis no apêndice (ALMEIDA, 2016).

Nossa ênfase compreende a oferta da leitura, sua mediação e um recorte dos possíveis efeitos contidos na materialidade mencionada. Desenvolveremos assim, a partir da apresentação da leitura, os eixos da mediação praticadas no espaço da FC, bem como o diálogo que propomos com as áreas de investigação citadas. Na sessão seguinte, apresentaremos o espaço da FC e o recorte dos dados analisados. Em seguida, verificaremos como o professormediador narra a sua experiência de leitura. Nas considerações finais, retomaremos as elaborações e apresentaremos as conclusões parciais a partir do recorte que fizemos da pesquisa de doutoramento onde este trabalho foi desenvolvido.

\section{A oferta da leitura: três eixos de mediação nos ciclos de leitura}

\section{A oferta da leitura}

A oferta é a primeira etapa do trabalho com a leitura. Por assim dizer, A Importância do Ato de Ler (1995), de Paulo Freire e O Direito à Literatura (2004), de Antonio Candido, embora sejam textos com uma série de diferenças entre si, das quais não nos cabe discutir aqui, em ambos, encontramos um núcleo comum em torno do qual giram nosso argumento: o acesso à leitura. Posto isso, os CMLLI podem contribuir para maior imersão literária na FC, ao estimular e promover a leitura individual e coletiva. Para isso, é preciso fomentar uma formação que aproxima a literatura da experiência pessoal. Nesse meandro, a oferta corrobora a investigação do modo como se circunscreve o professor no espaço entre a leitura e a literatura em relação aos seus aprendizes. Afinal, está no escopo dos objetivos da FC produzir impactos na educação básica.

De acordo com a professora e pesquisadora da pedagogia e do ensino, Vera Freitas (2012), as funções do professor de articular seu saber, instigar e facilitar a leitura, além de atribuir sentido a essa experiência, aglutinam-se numa metodologia: na mediação. Ao adotar essa metodologia na condução da leitura, o professor media o que "[...] acontece na dinâmica da interação" (FREITAS, 2012, p. 68). Nela o texto literário assume fundamental importância, afinal, nesse artefato a letra se insere no mundo em grau máximo, requerendo uma abordagem que amplie o ato de ler, redimensionando-o à instância da experiência, conforme corrobora ainda o professor de literatura Rildo Cosson. Autor do livro Letramento Literário: Teoria e Prática (2019), Cosson discute a importância da sistematização do ensino de literatura na educação básica, visando o desenvolvimento da compreensão de leitura. O papel dessa prática é aproximar a realidade que cerca os leitores do universo feito de palavras.

Segundo Cosson (2019), o letramento acontece em dois momentos, no da decodificação, durante a etapa de alfabetização, e no literário, em que a decodificação é atualizada pela leitura literária. Dizendo de outro modo, nesse segundo letramento, a leitura precisa transpor-se do nível do código da língua para o nível do significado, alçando a "extração do sentido que está no texto" 
(COSSON, 2019, p. 39). Sendo assim, ao professor-mediador cabe desenvolver estratégias que dinamizem esse processo. Em relação a essa dinâmica da mediação iniciada pela oferta da leitura, no artigo de Rosilene Silva Vale (2020), uma das professoras-participantes da FC em coautoria com Almeida e Neves, apresenta a Figura 1 que ilustra os movimentos da mediação de leitura em LI realizada em suas aulas em uma escola da região metropolitana de Belo Horizonte. A professora narra os desdobramentos da oferta da leitura no contexto de uma escola pública, ao passo que contrasta a metodologia que praticava antes de fazer parte da FC com a atual. As resistências e os desafios que se seguem ao movimento da oferta são atravessados por uma intensa interlocução da professora com os alunos acerca da importância da leitura e do aprendizado da língua. Assim, o registro do processo, o tempo de leitura e as tarefas de suporte são orientadas para agregarem sentido à leitura, de modo que os próprios alunos percebam os impactos e os possíveis desenvolvimentos advindos da experiência com a leitura.

\section{FIGURE 1 - READING MEDIATION MOVEMENTS}

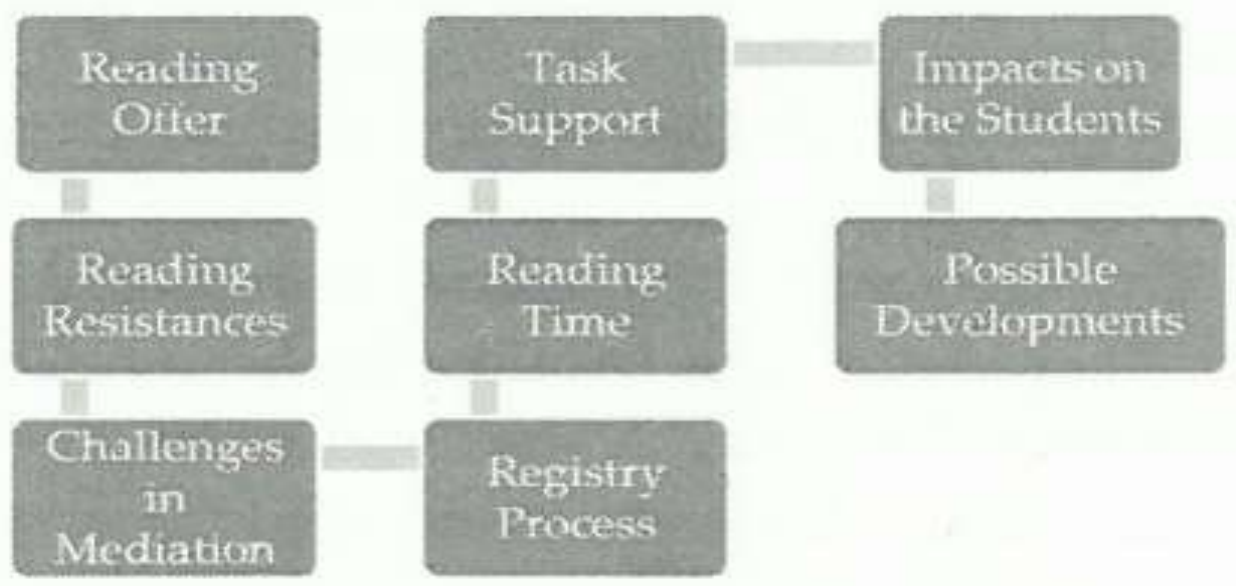

Figura 1: Movimentos da mediação de leitura - Fonte: Almeida, Vale e Neves, 2020, p. 177

Conforme ilustra a figura 1 o processo de mediação passa por etapas que circunscrevem a singularidade do fazer docente da professora, e que ao longo de sua carreira percebeu que as resistências à leitura geram desafios em sua mediação e, como contrapartida, os registros do processo modificam a postura dos estudantes e os convoca à agência da leitura. Em consonância com esses movimentos, apresentamos o circuito do processo de mediação realizado nos CMLLI, representado por três eixos: a oferta da leitura já explorada, a interação e a apropriação do texto, em sequência.

\section{A interação com a leitura}

No segundo eixo da mediação de leitura, onde ocorre a interação, o corpo do mediador ganha destaque pois sua performance de mediação emprega sua voz, sua subjetividade e suas intenções. Como se verá a partir de então, os termos mediação literária e performance, por vezes, ocorrerão intercambiados, pois compreendemos que no âmbito de um trabalho interdisciplinar como este, ambos termos são passíveis de nomear a dinâmica da leitura que propomos na FC.

Nesse ínterim, os diálogos entre a língua e literatura inglesa, a psicanálise e a pedagogia do teatro fundaram a possibilidade de ofertar-se encontros orientados para a experimentação e a realização de mediações literárias performáticas na FC, tendo como objetivo a replicação 
no espaço escolar em que atuam os professores. Sendo assim, chamamos de ciclos cada convite de leitura, reflexão e espaço para a tomada de consciência de que professores em formação são professores formadores em potencial.

No dicionário Aurélio (FERREIRA, 1999), a palavra ciclo significa uma "série de fenômenos que se sucedem numa ordem determinada. Sequência de fenômenos que se renovam periodicamente" (p. 161). Nos CMLLI foi possível perceber o trânsito entre os três eixos citados na interação, por se pressupor nos corpos do mediador e do espectador, o estatuto de performance. Afinal, os ciclos são compostos por meio de um conjunto de ações corporais, vocais e sensoriais em consonância com o texto dramatúrgico.

Essa vivência inaugura uma performance, pois convoca uma ação para um espectador (SCHECHNER, 2006). O plano de ação convida à interação, tratando-se portanto, de uma ação coletiva. Para isso, o professor-mediador realiza na performance uma interação com o sentido do texto atravessando sua subjetividade. Desse modo, os docentes passam a experienciar a leitura pela via subjetiva, pois que, como diagnostica Mariza Perobelli (2013), no texto Formação de professores: uma experiência teatral lúdica, o desafio de acessar a subjetividade dos professores em FC é bem grande, uma vez que, ao longo do processo de formação inicial (FI), os professores não são muito estimulados a explorar seu potencial criativo. Segundo ela, a formação que proporciona vivências que sensibilizam artisticamente ampliam as possibilidades do ensino-aprendizagem.

Para esses efeitos, a replicação das práticas docentes que restringem a relação com o saber precisa ser superada. Nesse sentido, durante o processo da interação, na FC as elaborações subjetivas dos professores-participantes em confluência com o texto dramatúrgico (os textos teatrais foram escolhidos previamente, pois os professores não tinham experiência com o gênero) são acolhidas e reelaboradas nos encontros por meio dos jogos teatrais ${ }^{4}$.

\section{A apropriação da leitura}

Por apropriação da leitura entendemos quando se inaugura uma nova "construção de sentido no mundo" (COSSON, 2019, p. 76). Esse terceiro eixo do circuito de mediação, pode ou não ocorrer no encontro do CMLLI, assim como pode ser verificável ou não, posto que a "circulação discursiva gera efeitos não necessariamente observáveis em um tempo cronológico" de acordo com a coordenadora do projeto ConCol (NEVES, 2021 p. 406). Assim, o docente pode investir em mediações alternativas na medida e ao longo de sua inserção ativa e reflexiva na FC. Espera-se que com a circulação discursiva os docentes tornem-se mais capazes de promover mudanças no espaço escolar pois, para Perobelli, o efeito é o de "provocar deslocamentos. Mudar as coisas de lugar. (...) Interromper as ações mecânicas. Possibilitar experiências. Abrir espaço. Dar-se tempo. Permitir o sensível” (2013, p. 219). Como consequência disso é possível fundar uma formação singular.

No processo da circulação discursiva a apropriação consiste em propiciar que os sujeitos ampliem seu repertório formativo e subjetivo, uma vez que na FC os professores refletem sobre sua própria trajetória e a dos demais e têm a oportunidade de deslocar, cada um, em seu tempo e seu modo singular das identificações cristalizadas nas queixas referentes ao sucateamento da educação brasileira. A docência requer profissionais conscientes de que a tarefa de mediar o conhecimento e o saber até então adquirido consiste em oferecer perguntas e promover autonomia. Assim, do processo de elaboração individual do professor, logra-se a apropriação, na medida em que sua abertura para uma leitura que dialogue com instâncias da vida pessoal esteja em proporção com o desejo de oferecer esse diálogo ao coletivo. Desse modo, a FC

\footnotetext{
${ }^{4}$ Para Koudela, “os jogos teatrais são ao mesmo tempo atividades lúdicas e exercícios teatrais que formam a base para uma abordagem alternativa de ensino e aprendizagem" (1999, p. 15).
} 
acolhe as inquietações, intervém de modo a despertar saídas criativas e amplia esses efeitos entre professores e demais participantes do projeto.

A seguir, descrevemos como os CMLLI na FC foram realizados enquanto apresentamos o Projeto Continuação Colaborativa.

\section{Metodologia}

O recorte dessa pesquisa tange apenas à descrição dos Ciclos de Jogos Teatrais e Leitura Dramática e dos Ciclos de Mediação de Leitura em Língua Inglesa na Formação Continuada. Foram realizados um total de 12 encontros em 2018 e 2019 no projeto ConCol. No CMLLI se veicula peças teatrais do teatro do absurdo ${ }^{5}$ (ESSLIN, 2018) com roteiro de mediação preparado por um professor-mediador. Uma performance é criada a partir de uma proposta de interação com a obra e os demais professores. Colaborativamente professor e orientador planejam as ações dos encontros. No primeiro momento, o pesquisador faz um convite a um membro do grupo que voluntariamente se dedica à leitura da obra e à elaboração de ações de mediação. No decorrer da elaboração, o professor-mediador seleciona aspectos da obra e estabelece articulações criativas dos signos com o roteiro de ações de mediação. As ações são construídas a partir dos efeitos dessa vivência "num [também] processo de auto pesquisa" (LEAL, 2013, p. 201).

$\mathrm{O}$ projeto ConCol conta com 37 professores participantes e 8 professores colaboradores, somando 45 membros. Há também a interação pela plataforma digital WhatsApp em que os participantes acompanham as atividades realizadas no projeto. Os encontros presenciais aconteciam ao longo do ano letivo, sempre às sextas-feiras das $13 \mathrm{~h}$ às $18 \mathrm{~h}$ no prédio CAD II (centro de atividades didáticas) na UFMG, mas a chegada do novo coronavírus no Brasil interrompeu os encontros presenciais. Com as medidas de isolamento social, os encontros passaram a ser realizados pela plataforma Zoom, em formato síncrono no mesmo dia e horário. $\mathrm{Na}$ programação do ConCol, durante o tempo da pesquisa, foram ofertados três eixos de formação: 1) a formação linguística (eixo de aulas de língua inglesa); 2) os pedagogical rounds (eixo reflexivo, criado por Loures (2014), que faz circular os saberes entre os participantes do projeto sob orientação dos princípios da psicanálise); e 3) os ciclos de mediação de leitura em LI.

Dentre os participantes do ConCol, 7 professores voluntariaram-se para participar como mediadores de 7 peças teatrais escritas por 3 dramaturgos, a saber: Samuel Beckett, Sarah Kane e Harold Pinter. Estes professores prepararam o roteiro durante o período de três a cinco encontros orientados pelo pesquisador. O Diário de Percurso (DP) contendo os Registro de Leitura dos Acontecimentos (RLA) geraram os dados para a pesquisa.

A seguir, nas análises, apresentamos uma breve descrição da elaboração de três performances que correspondem, cada uma, a um dos três ciclos de leitura realizados, e, respectivamente, apresentaremos uma síntese das ações desenvolvidas e os possíveis efeitos subjetivos advindos da experiência no tempo lógico (LACAN, 1998) da formação. Lacan, neste texto, de acordo com Neves, "pretende mostrar a lógica intersubjetiva de uma elaboração antes da tomada de decisão" que desprende o sujeito das identificações cristalizadas (2021, p. 407). Essa elaboração subjetiva consiste em três tempos; a saber, o instante de olhar, o tempo para compreender e o momento de concluir, de forma que em cada um a certeza do sujeito se oriente e se modifique até que seja resgatada e ressignificada para daí se depreender um novo saber. O tempo lógico é subjetivo, e difere, portanto, do tempo cronológico, que é contínuo e objetivo. Como resultado da escuta de professores foram apreendidos recortes discursivos a partir dos pedagogical rounds (PR) nos momentos de avaliação das experiências. Durante os PRs, temos a oferta da palavra (com base na

\footnotetext{
${ }^{5}$ De acordo com Martin Esslin, o teatro do absurdo responde ao mundo do pós-guerra com a desolação, o silêncio, a mutilação, a ausência de linearidade e fragmentação dos diálogos e da peça dramatúrgica em si.
} 
associação livre, (FREUD, 1996), a escuta dos professores e intervenção livre nas queixas apresentadas, levando-os à responsabilização no fazer docente (LOURES, 2014).

\section{Análises da materialidade discursiva gerada no diário de percurso}

\section{A proposta de mediação dos ciclos na formação continuada}

Nesta seção, partiremos de uma análise global de cada ciclo apresentando a síntese de cada percurso. No I Ciclo de Jogos Teatrais e Leitura Dramática foi possível notar que as ações de mediação estavam muito segmentadas. Os encontros foram divididos em três momentos, a saber: no primeiro, os professores apresentavam uma performance seguida de um breve relato da experiência de elaboração da performance e um jogo teatral de sensibilização. No segundo momento, eram feitas leituras complementares a respeito do dramaturgo ou peça, a exibição de um vídeo sobre fonética, a sensibilização e a exibição de uma montagem filmada da peça teatral. No terceiro momento, realizavam uma leitura silenciosa de trechos da peça. Após a leitura, os professores eram convidados a lerem em duplas enquanto se movimentavam pelo espaço da sala, usando a voz e interagindo com os demais membros do grupo. O encontro finalizava com um momento de avaliação da experiência por meio de comentários sobre o desempenho do professor e os temas da peça dramatúrgica. Ressaltamos que o primeiro Ciclo foi mediado pelo pesquisador, um(a) professor(a) voluntário(a) e uma monitora de extensão. Entretanto, percebemos muita resistência dos professores, pois constantemente afirmavam terem dificuldade de interpretar os textos, não os compreendendo ou não se sentindo autorizados a ler o texto com o corpo. Assim, decidimos mudar o título de Ciclo de Jogos Teatrais e Leitura Dramática para Ciclo de Mediação de Leitura em Língua Inglesa, embora continuássemos a desenvolver os ciclos com o suporte da Pedagogia do Teatro.

No segundo CMLLI, o professor que antes encontrava dificuldade em assumir o protagonismo como professor-mediador, passa a assumi-lo durante todo o encontro. Mantémse a estrutura dividida em três momentos, mas as ações passam a ser mais integradas. No primeiro momento, o professor-mediador iniciava com uma reflexão relativa ao tema da peça ou alguma contextualização breve e apresentava uma performance a partir de uma releitura da obra. No segundo momento, fazia a mediação adentrando na peça e relatava seu processo de elaboração. O terceiro momento se seguia com uma atividade de interação com o texto, em formato individual ou em pequenos grupos com o uso do sussurrofone (um dispositivo adaptado pela professora Luciene de Castro Gomes a partir do aparelho whisper phone ${ }^{6}$ ). Eram feitas leituras em voz alta, a avaliação e, ao final, os comentários sobre o desempenho de leitura.

O terceiro CMLLI na FC realizado no segundo semestre de 2019, em contraste com o primeiro, e em confluência com o segundo, inaugura o que podemos chamar de uma mediação mais fluida. Percebemos que os encontros de mediação ocorreram com maior fluidez na medida em que os professores-mediadores eram tocados em suas subjetividades. Assim, gradativamente nos ciclos posteriores, o pesquisador foi encontrando vias de acesso às subjetividades dos professores-mediadores e demais professores. Neste caso, a elaboração do roteiro de mediação tornou-se mais latente pelo professor-mediador, pois a performance acontecia durante todo o encontro. Podemos afirmar que a análise do texto teatral apresenta implicações diretas com a

\footnotetext{
${ }^{6} \mathrm{O}$ sussurrofone é uma adaptação do whisper phone, ferramenta que permite a captação individual da voz com ampliação do som. Feito de PVC, ele aumenta o volume da fala em até 10 vezes, embora o retorno do som ocorra apenas para quem utiliza o instrumento. Conhecemos o sussurrofone através da criativa adaptação feita pela professora Lucienne de Castro Gomes, uma das participantes do ConCol. Para mais informações: https://catracalivre.com.br/educacao/engenhoca-leitura/. Acesso em: 18 out. 2021.
} 
trajetória do docente e outros aspectos de sua vida pessoal. Os professores-espectadores tornamse professores-participantes ativos no processo. Como veremos na ilustração abaixo, chamamos esses momentos de movimentos do Circuito de Mediação Literária no ConCol. Eles são didaticamente organizados em: oferta, interação e apropriação.

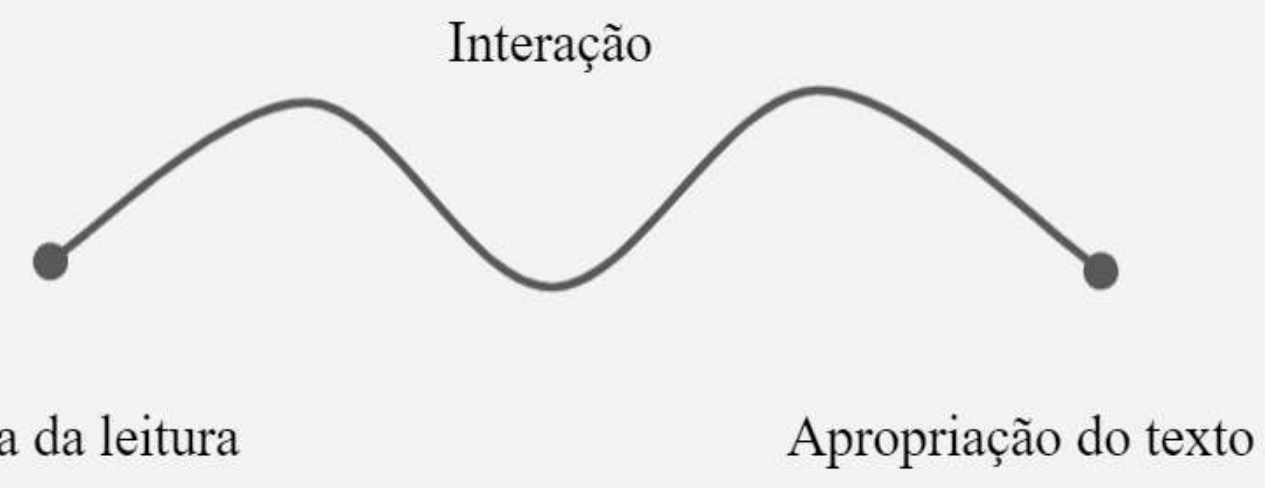

Oferta da leitura

Apropriação do texto

Figura 2: Circuito de mediação literária no ConCol - Fonte: Os autores

A construção desse circuito advém da observação dos ciclos, dos diálogos entre pesquisador, orientadora e monitora, além da escuta da materialidade discursiva. A representação de um circuito cuja forma apresenta ondulações é uma tentativa de ilustrar a não-linearidade do processo de mediação literária. Como veremos, a interação pode anteceder a oferta e a apropriação, por sua vez, deste e daquele. Cabe-nos resguardar a ressalva de que notamos, entretanto, uma correspondência enfática nos encontros finais de cada ciclo com os três eixos do circuito. Pretendemos com essa aproximação de correspondência salientar o aspecto da mediação que mais ressoa a partir de cada ciclo de leitura. Para esclarecer essa correspondência selecionamos excertos da materialidade discursiva e fotos dos respectivos encontros que reiteram a indissociabilidade da teoria da mediação e sua realização. Em sequência, apontamos para os possíveis efeitos subjetivos que os recortes discursivos e o andamento dos ciclos apontam.

\section{Possíveis efeitos subjetivos advindos da experiência nos ciclos}

No contexto do $3^{\circ}$ Encontro do Primeiro CMLLI na FC, a professora-mediadora realizou uma performance baseada na peça dramatúrgica Fim de Partida ${ }^{7}$, que apresenta quatro personagens mutilados e cuja ligação parental liga apenas três deles, pois o terceiro, Clov é um criado e, embora expresse ao longo de toda a peça seu desejo de ir embora dali, a vista da janela não lhe oferece alento melhor. Na imagem abaixo ela está sentada no chão manipulando objetos de uma mesa de jantar; os dois pratos levam plaquinhas de papel com os nomes dos personagens Nagg e Nell, o casal de idosos, pais do protagonista Hamm. Flores vermelhas em um copo estão ao centro e a professora as manipula enquanto um áudio gravado por ela de um fragmento do texto dramatúrgico é reproduzido.

\footnotetext{
${ }^{7}$ Peça teatral do dramaturgo irlandês Samuel Beckett. In: The Complete Dramatic Works. London: Faber and Faber, Ltd: 1986.
} 


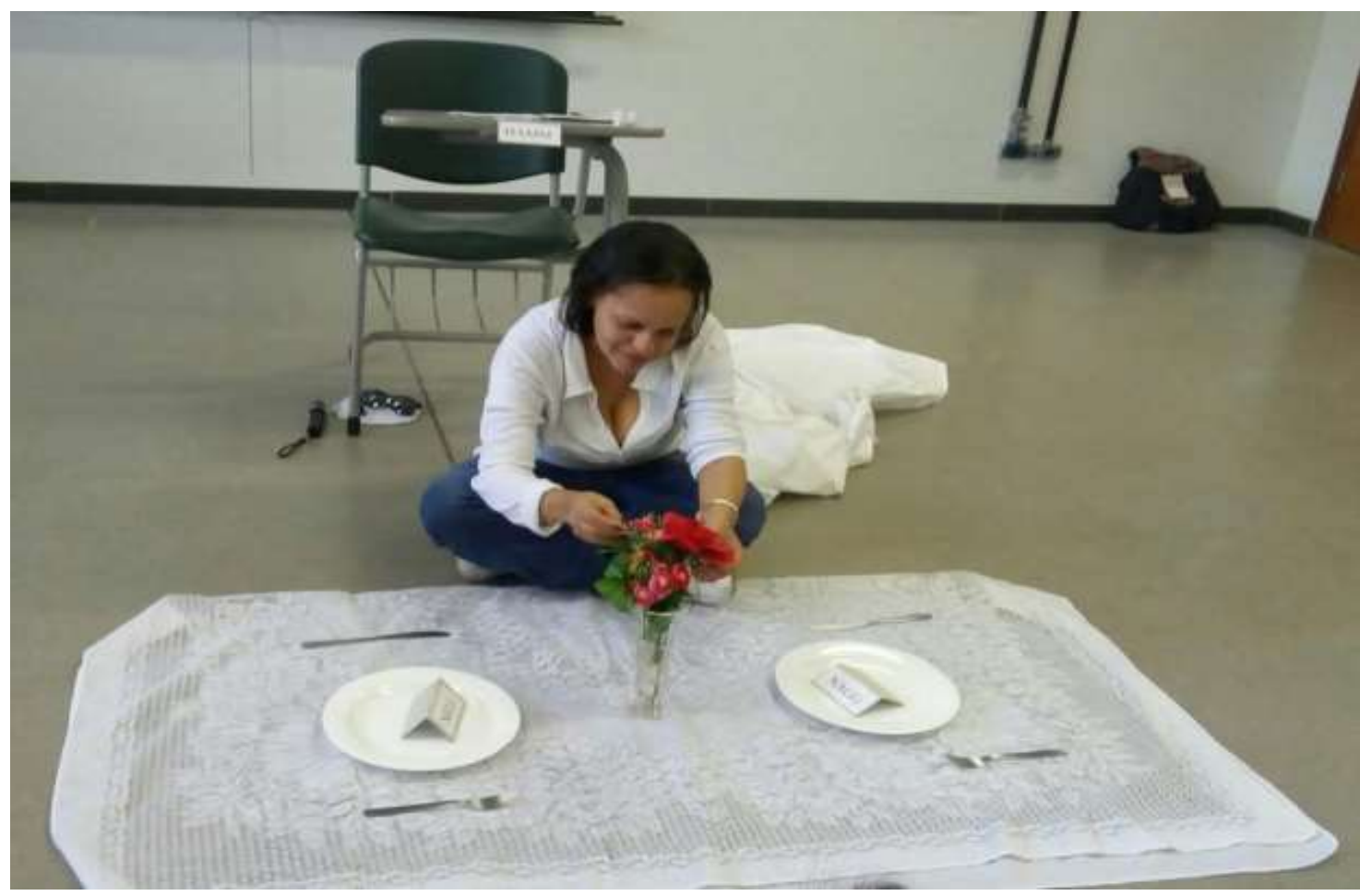

Figura 3: $3^{\circ}$ Encontro do Primeiro Ciclo de Mediação de Leitura em LI na FC - Fonte: Os autores

A inserção desses elementos nos permite dizer que a performance da professora (P2) concentra-se em uma espécie de contextualização que ilustra o texto de referência. Já em um outro momento, ela convida um professor-participante para interagir com ela na performance. Ela indica gestualmente à colega que suba na cadeira e leia um fragmento do texto previamente selecionado e a ação se repete com as posições entre elas invertidas. Quando a professora-mediadora nos relata a experiência, ela diz o que quis mostrar à colega no momento de interação com ela.

\section{Recorte discursivo 1. Professora 2}

P2: Quando eu convidei ela para / e coloquei-a / eu / mostrei que Hamm / era muito: Pa: Rigoroso. (tradução nossa)

\section{$3^{\circ}$ Encontro do Primeiro Ciclo de Mediação de Leitura em LI na FC}

Como se pode perceber, a relação de poder e opressão entre os personagens Hamm e Clov é apresentada na performance demonstrando que sua intenção de leitura é comunicar a peça, confirmando assim, que sua mediação literária efetiva o eixo da oferta de leitura, o movimento inicial do circuito de mediação de leitura.

No $6^{\circ}$ Encontro do II Ciclo de Mediação de Leitura, a professora-mediadora propõe uma performance que conjuga a dificuldade de leitura dos diálogos fragmentados do texto, com o jogo teatral a partir da peça $\mathrm{Crave}^{8}$, que sugere nos diálogos das quatro personagens relações conflituosas e contraditórias de dor e prazer, violência, estupro e vícios. O recorte discursivo descreve esse jogo e uma foto ilustra esse momento do encontro. Nela, a professora está com os braços estendidos no centro da sala de aula e de costas para os professores-participantes que estão também de pé formando dois pequenos grupos em semicírculo. Eles carregam nas mãos o fragmento textual a ser lido no jogo, e têm à frente projetado no quadro os comandos desse jogo. No chão, estão dispostos os nomes dos personagens da peça A, B, C e M.

\footnotetext{
${ }^{8}$ Peça teatral escrita pela dramaturga inglesa Sarah Kane, publicada originalmente em 1998. Disponível em: http://pt.scribd.com/doc/38655660/Sarah-Kane-Crave. Acesso em: 18 out. 2021.
} 


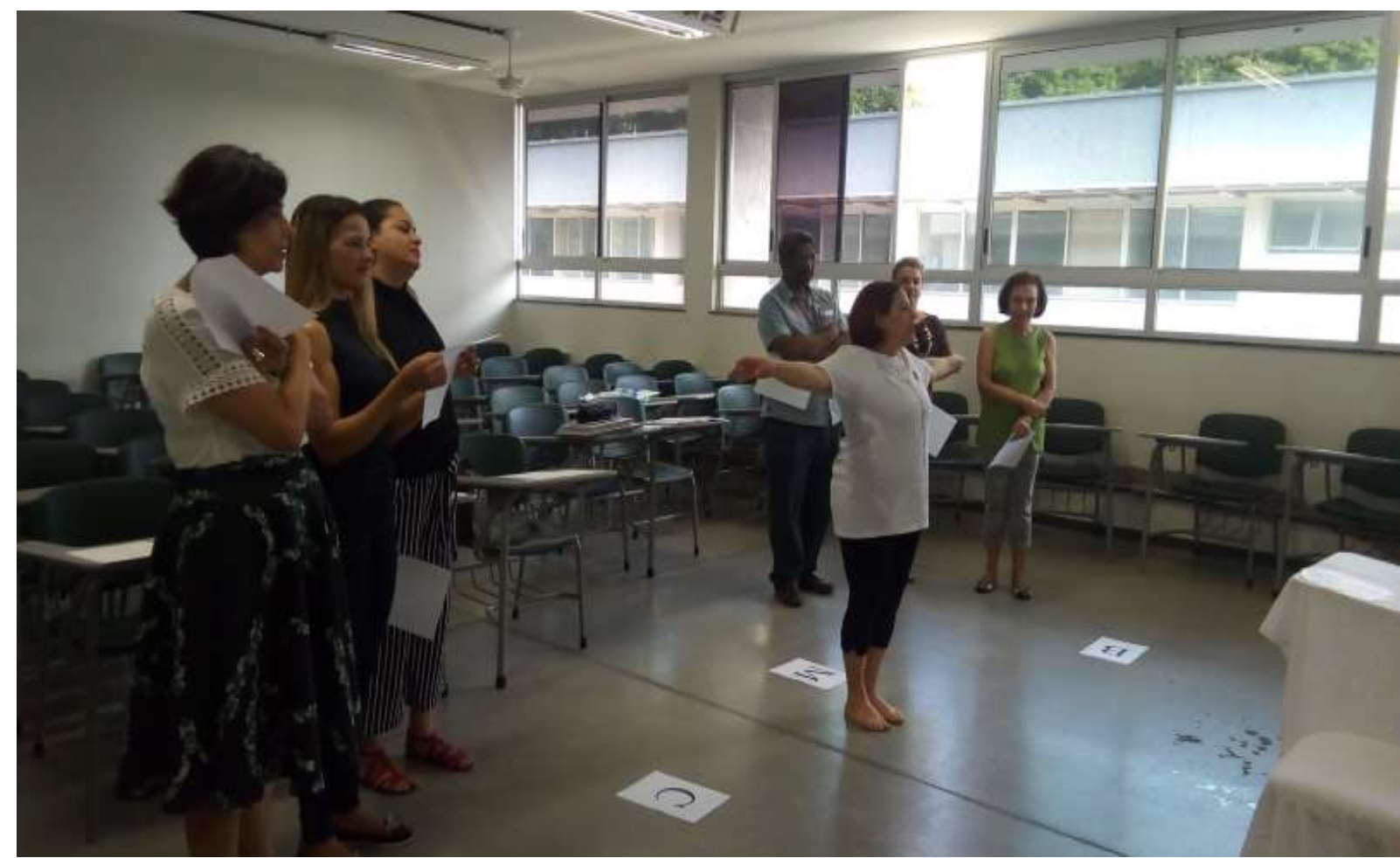

Figura 4: $5^{\circ}$ Encontro do Segundo Ciclo de Mediação de Leitura em LI na FC - Fonte: Os autores

\section{Recorte discursivo 2. Professora 5}

P5: Durante a elaboração da performance nós criamos um jogo. É: CHOIR OF READING. Coro de leitura. Eu gostaria de convidar vocês a participarem desse jogo. Esse jogo tem uma proposta do leitor-espectador ler e interagir com o texto de Sarah Kane.

\section{$5^{\circ}$ Encontro do Segundo Ciclo de Mediação de Leitura em LI na FC}

A proposta de interação através do jogo de coro de leitura representa o momento em que os ciclos de leitura passam a incorporar o coletivo à performance. Os professores-participantes que nos ciclos anteriores assistiam sentados e distantes, são a partir de então convidados a integrar a ação e lerem juntos o texto de acordo com os gestos de comandos de intenção de voz e expressão dados pela professora-mediadora. Desse modo, de acordo com o nosso circuito, o jogo além de ofertar a leitura promove a interação e, este antevê o eixo da apropriação da leitura conforme ilustramos na performance a seguir.

O III CMLLI na FC encerra no $4^{\circ}$ encontro com a performance baseada na peça Silêncio ${ }^{9}$ que apresenta diálogos entre Ellen, Rumpsey e Bates expressam a complexidade do interesse afetivo e de relacionamentos amorosos. Seus diálogos são entrecortados por devaneios e lembranças que provocam o silêncio repetidas vezes ao longo da peça. $\mathrm{O}$ encontro com o outro de maneira silenciosa gera a performance ilustrada pela imagem em que as professoras estão sentadas em um semicírculo vestidas de máscaras enquanto o professor-mediador está sentado de frente para elas. Nesse momento da performance ele observa em silêncio cada professora, deslocando-se de modo a ficar posicionado exatamente em frente a cada uma por vez. Nessa proposta de interação o professor extrai o silêncio tratado na peça e o ressignifica através do jogo. No recorte discursivo a seguir ele relata sobre a experiência de leitura que espelha a sua proposta de interação no coletivo.

\footnotetext{
${ }^{9}$ Obra do dramaturgo britânico Harold Pinter. In: Landscape and Silence. London: Eyre Methuen, 1970.
} 


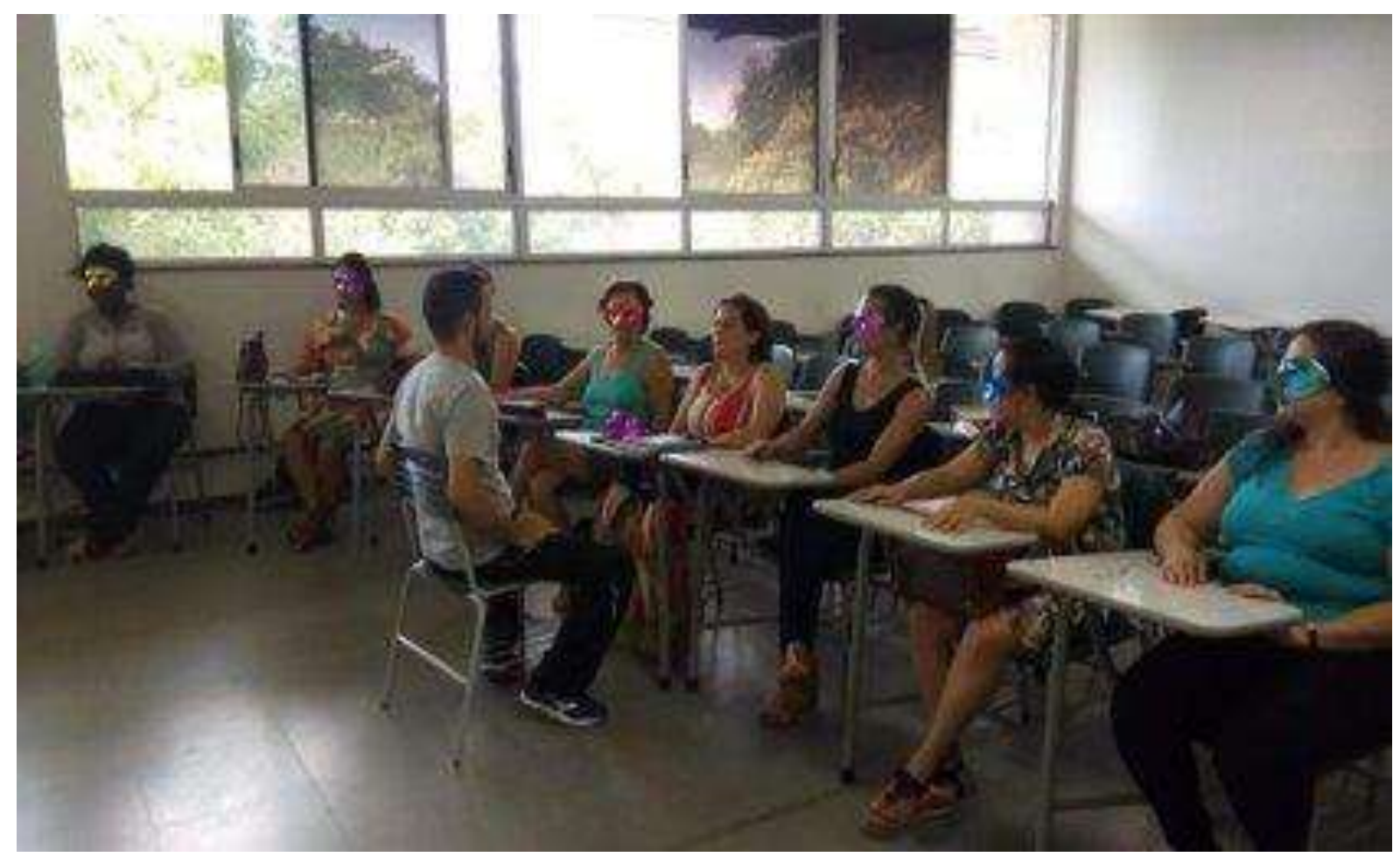

Figura 5: $4^{\circ}$ Encontro do Terceiro Ciclo de Mediação de Leitura em LI na FC - Fonte: Os autores

\section{Recorte discursivo 3. Professor 7}

P7: Então eu achei assim, que eu não esperava, na minha primeira leitura que fosse mexer com as memórias, e me fazer pensar nos meus silenciamentos.

$4^{\circ}$ Encontro do Terceiro Ciclo de Mediação de Leitura em LI na FC

O trecho elucida o silêncio presente nas relações entre as personagens da peça e a correlação da ação do jogo com as máscaras sinalizando que essas últimas e o silêncio metaforizam o algo desconhecido nos outros. Por assim dizer, a oferta e a interação partiram do eixo de apropriação do significado do texto operado pelo professor, levando-nos a perceber que os movimentos da mediação literária, assim como o próprio deslocamento do tempo lógico dos sujeitos não ocorrem em consonância com a causalidade do tempo cronológico. O acontecimento literário concretiza, "um diálogo entre autor e leitor mediado pelo texto" (COSSON, 2019, p. 40) diálogo este que, somado às impressões de leitura, visa comunicar uma interpretação latente e singular.

O primeiro nível da mediação acontece pela via da experiência. O professor-mediador é atravessado subjetivamente durante a elaboração da performance. Como consequência disso, as performances descritas expressam esse atravessamento e o esforço de inserção ativa do coletivo de professores. Os três professores-mediadores analisados revelaram em comum essa interferência da subjetividade na mediação literária. Em síntese, no recorte 1, em que observamos a associação feita pela professora-mediadora com os personagens da peça Fim de partida com seu contexto familiar. No recorte 2, a dificuldade de leitura da peça dramatúrgica relatada pela professora é superada quando sua performance convoca uma leitura coletiva. No recorte 3, o professor-mediador fala sobre os seus próprios silenciamentos para introduzir a peça Silêncio do dramaturgo inglês Harold Pinter. 


\section{Conclusão}

A FC no Projeto ContinuAÇÃO Colaborativa através da pesquisa de doutoramento de Almeida (2021) reitera dentre outras coisas a importância do acolhimento da comunidade externa na academia. Por conseguinte, ela também ressoa, embora de maneira singular, outras ações de FC presentes no Brasil, cujo intuito é ampliar o engajamento de professores na sociedade. A singularidade desta ação compreende a interdisciplinaridade convocada para integrar a mediação de leitura, assim como a estruturação dos planos de mediação construídos a partir das escolhas dos professores-mediadores. O recorte do percurso das ações dos CMLLI neste artigo analisados sugerem que a oferta da leitura que implica em uma mediação colaborativa é fundamental tanto para o histórico do projeto quanto para a trajetória dos professores, uma vez que, espera-se gerar impactos na prática da sala de aula das escolas em que eles atuam. Infelizmente, os ciclos não foram vivenciados nas escolas, pois apenas alguns professores promovem a leitura no contexto de ensino remoto, ocasionado pela pandemia de COVID-19 nos anos de 2020 e 2021.

Reiteramos que nossas conclusões neste trabalho são parciais, na medida em que ele se refere a somente um recorte dos ciclos de leitura. No entanto, podemos dizer ainda que, com a criação do circuito de mediação, realizamos um balanço analítico dos ciclos. Além de representar o processo de mediação, a respectiva correspondência dos ciclos com os eixos desdobra-se ainda em outra análise. Como observamos no I Ciclo, a performance de mediação ocupava apenas a parte inicial do encontro, limitando assim a proposta de interação e até mesmo a leitura, uma vez que os fragmentos textuais foram explorados de maneira representativa. Já o II Ciclo, a performance buscou integrar as ações por todo o encontro, tendo como ápice a proposta de interação que utiliza um jogo teatral sinestésico e coletivo. Essa configuração permite-nos dizer que a dificuldade de leitura individual foi ressignificada por uma leitura coletiva. Por fim, no III Ciclo, com a apropriação do significante silêncio, a proposta de interação converge na leitura pautada em uma reflexão da condição humana. Desse modo, a partir dos ciclos podemos verificar que a oferta da leitura possibilita um diálogo com as especificidades dos sujeitos assim como da coletividade em que os professores se inserem. Cada um dos doze encontros dos três ciclos de leitura, de maneira geral, convocaram os professores a uma leitura tanto literária quanto da própria trajetória cujo denominador comum é a FC. Podemos dizer ainda, que eles utilizaram o espaço de mediação literária como um exercício para fomentar a prática de ensino de leitura na FC. Em vista disso, concluímos por ora, que a exposição à leitura combinada à mediação seja no espaço da FC ou fora dele, contribui para a promoção de experiências semelhantes no espaço escolar, fazendo com que os docentes sejam agentes da transformação educacional brasileira

\section{Referências}

ALMEIDA. J. S. V. Efeitos de sentido e singularidade no processo de escrita autobiográfica em língua inglesa. 2016. 191f. Dissertação (Mestrado em Estudos Linguísticos) - Faculdade de Letras, Universidade Federal de Minas Gerais, Belo Horizonte, 2016.

ALMEIDA. J. S. V.; VALE. R. S.; NEVES. M. S. The presence of reading in the trajectory and in the continuing education of an EFL teacher. In: RICHTER. C. L. NÓBREGA. D. G. SOUZA. F. M. NASCIMENTO. J. F. (Org.). Language teaching learning in the $21^{\text {st }}$ century. São Paulo: Mentes Abertas, 2020. p. 171-180.

CANDIDO, A. O direito à literatura. In: CANDIDO, A. Vários escritos. 4 ed. São Paulo: Duas Cidades, 2004. p. 169-191. 
CASTILHO, A. T. A língua falada no ensino do português. São Paulo: Contexto, 1998

COSSON, R. Letramento literário: teoria e prática. São Paulo: Contexto, 2019.

ESSLIN, M. O teatro do absurdo. Rio de Janeiro: Zahar, 2018

FERREIRA. A. B. H. Novo Aurélio século XXI: o dicionário da língua portuguesa. 1. ed. Rio de Janeiro: Nova Fronteira, 1999.

FREITAS, V. Mediação: estratégia facilitadora da compreensão leitora. São Paulo: Parábola, 2012.

FREIRE, P. A importância do ato de ler. Campinas: Mercado das Letras, 1995.

FREUD, S. Recordar, repetir e elaborar. In: FREUD, S. Obras psicológicas completas de Sigmund Freud: edição standard brasileira. v. 12. Rio de Janeiro: Imago, 1996. p. 191-203.

KOUDELA, I. Texto e jogo: uma didática brechtiana. São Paulo: Perspectiva, 1999.

LACAN, J. O tempo lógico e a asserção da certeza antecipada: um novo sofisma. In: LACAN, J. Escritos. Trad. V. Ribeiro. Rio de Janeiro: Jorge Zahar, 1998. p. 197- 213.

LEAL, M. L. Pedagogia da performance: uma experiência. In: TELLES, N. (Org.). Pedagogia do teatro: práticas contemporâneas na sala de aula. Campinas: Papirus, 2013. p. 197-217.

LOURES. G. F. O manejo da transferência na formação continuada de professores de inglês: um estudo de caso. 2014. 192f. Tese (Doutorado em Linguística Aplicada) - Programa de PósGraduação em Linguística, Universidade Federal de Minas Gerais, 2014.

NEVES. M. S. A intervenção psicanalítica na integração da pesquisa e da extensão com professores em formação continuada. In: SILVA, D; BERTOLDO, E. S; LEITE, J. D; GOMES, V. A. (Org.) E por falar em intervenção... Campinas: Pontes, 2021. p. 401-424.

PEROBELLI, M. Formação de professores: uma experiência teatral lúdica. In: TELLES, N. (Org.). Pedagogia do teatro: práticas contemporâneas na sala de aula. Campinas: Papirus, 2013. p. 219-238

SCHECHNER, R. O que é performance? In: SCHECHNER, R. Performance studies: an introduction. 2 ed. New York \& London: Routledge, 2006. p. 28-51.

SPOLIN, V. Jogos teatrais: o fichário de Viola Spolin. Trad. I. D. Koudela. São Paulo: Perspectiva, 2006.

\section{Sobre os autores}

Lady Lourdes Soares Medeiros. Graduanda em Estudos Literários na Faculdade de Letras da Universidade Federal de Minas Gerais (UFMG). Foi monitora de extensão no Programa Interfaces da Formação em Línguas Estrangeiras no Projeto ContinuAÇÃO Colaborativa (CONCOL) nos anos de 2018 e 2019. Tem experiência com mediação literária em língua inglesa e pesquisa acadêmica. E-mail: ladylourdesm46@gmail.com. 
Jackson Santos Vitória de Almeida. Licenciado em Língua Inglesa e Literaturas pela Universidade do Estado da Bahia (UNEB) e Língua Portuguesa pelo Centro Universitário Claretiano. Especialista em Tradução de Inglês pela Universidade Estácio de Sá. Mestre em Estudos Linguísticos pela Universidade Federal de Minas Gerais (UFMG). Ator pela Escola de Teatro da Pontifícia Universidade Católica de Minas Gerais. Atualmente, é doutorando em Estudos Linguísticos na UFMG. Tem experiência como professor de inglês e tutor no formato semipresencial em cursos de idiomas, escolas regulares e universidade. Atua principalmente nos seguintes temas: formação de professores de línguas adicionais, literatura inglesa, mediação literária, dramaturgia, encenação, interpretação, pedagogia do teatro, performance, psicanálise Freudo-lacaniana e linguística da enunciação. Atua como colaborador voluntário em três projetos, a saber: Projeto ContinuAÇÃO Colaborativa (desde 2014), Catalisa - Rede de Cooperação para Sustentabilidade (desde 2017) e no Projeto Biblioteca Comunitária, Leitura, Cultura e Arte (2021). E-mail: vitorioso8@hotmail.com.

Maralice Souza Neves. Professora Titular da Faculdade de Letras da Universidade Federal de Minas Gerais (UFMG). Psicóloga pela Universidade Federal de Minas Gerais (1982). Licenciada em Letras- Inglês pela Universidade Federal de Minas Gerais (1988). Mestre em Letras - Inglês pela Universidade Federal de Minas Gerais (1993) e Doutora em Linguística Aplicada pela Universidade Estadual de Campinas (2002). Atua no Programa de Pós-Graduação em Estudos Linguísticos (POSLIN), vinculada à área de Linguística Aplicada orientando pesquisas de Iniciação Científica, Mestrado e Doutorado. Líder do Grupo de Pesquisa Educação e Aprendizagem de Línguas Estrangeiras do CNPq. Membro do GT Práticas Identitárias em Linguística Aplicada da Associação Nacional de Pós-Graduação e Pesquisa em Letras e Linguística (ANPOLL) desde 2002. Membro do GT Psicanálise e Educação da Associação Nacional de Pós-Graduação e Pesquisa em Psicologia (ANPEPP) desde 2014. Professora Residente do Instituto de Estudos Avançados Transdisciplinares (IEAT) da UFMG em 20162017. Atua na área de Linguística Aplicada aliando ensino, pesquisa e extensão à formação em Psicanálise. Atuação profissional de caráter interdisciplinar em análise de discurso, psicanálise, leitura, escrita, ensino/aprendizagem de línguas estrangeiras, formação de professores de línguas estrangeiras, educação continuada de professores, identidade, subjetividade.

E-mail: maraliceneves@gmail.com. 